\title{
Use of the disulfiram/copper complex for breast cancer chemoprevention in MMTV-erbB2 transgenic mice
}

\author{
YANHUI YANG ${ }^{1}$, QIAN DENG ${ }^{2}$, XIAOSHAN FENG ${ }^{3}$ and JUNJUN SUN ${ }^{1}$ \\ ${ }^{1}$ Department of General Surgery, The First Affiliated Hospital of Henan University of Science and Technology, Luoyang, \\ Henan 471003; ${ }^{2}$ Department of Pharmacy, The Central Hospital of Luoyang, Luoyang, Henan 471000; ${ }^{3}$ Department of Oncology, \\ The First Affiliated Hospital of Henan University of Science and Technology, Luoyang, Henan 471003, P.R. China
}

Received April 27, 2014; Accepted January 22, 2015

DOI: $10.3892 / \mathrm{mmr} .2015 .3426$

\begin{abstract}
The disulfiram/copper complex (DS/Cu) has been demonstrated to exert potent anti-tumor effects in various types of cancer. At present, whether DS/Cu has chemopreventive effects on breast cancer development remains to be fully elucidated. In the present study, using MMTV-erbB2 transgenic mice, it was identified for the first time that DS/Cu treatment was able to inhibit cell growth in breast cancer cells while sparing normal cells in vitro, in addition to delaying the development of mammary tumor development in MMTV-erbB2 transgenic mice in vivo. Morphological examination demonstrated that $\mathrm{DS} / \mathrm{Cu}$ treatment resulted in cell proliferation inhibition and apoptosis activation in vitro and in vivo. Furthermore, the present study observed that $\mathrm{DS} / \mathrm{Cu}$ may inhibit proliferation via inhibition of AKT and cyclin D1 signaling and promote apoptosis via c-Jun $\mathrm{N}$-terminal kinase activation and suppression of nuclear factor $\kappa \mathrm{B}$ signaling. These results suggested that $\mathrm{DS} / \mathrm{Cu}$ treatment may be a promising therapy for the prevention of erbB2-positive breast cancer.
\end{abstract}

\section{Introduction}

Breast cancer is the most common cancer in female adults worldwide and its incidence is rising (1). Although significant advances have been achieved in therapeutic strategies for breast cancer, it remains to be the cancer type with the second highest rate of mortality (1). Breast cancer is a complex process with a long latency; thus, chemoprevention aiming to prevent, reverse or delay carcinogenesis may benefit patients by reducing cancer risk and the need for invasive interventions (2).

In clinical practice, erbB2 is amplified and overexpressed in $\sim 30 \%$ of human breast primary tumors, and these tumors

Correspondence to: Dr Junjun Sun, Department of General Surgery, The First Affiliated Hospital of Henan University of Science and Technology, 24 Jinghua Road, Luoyang, Henan 471003, P.R. China

E-mail: jjsyfy@163.com

Key words: breast cancer, disulfiram, copper, apoptosis tend to have poor prognosis (3). Following several clinical trials, the US Food and Drug Administration (FDA) approved tamoxifen in 1997 and raloxifene in 2007 for breast cancer chemoprevention (4-6). However, to date, the use of tamoxifen and raloxifene for primary breast cancer chemoprevention in the US has remained low due to their side effects (2). Thus, it is important to investigate novel chemopreventive agents and intervention strategies for patients with breast cancer, particularly for those with erbB2-positive cancer.

In the etiology and progression of breast cancer, the protein kinase B (AKT) and c-Jun N-terminal kinase (JNK) signaling pathways have been suggested to participate in cell proliferation, migration, angiogenesis and protection against apoptosis $(7,8)$. It is widely accepted that activation of AKT through phosphorylation can inhibit proliferation in tumor cells (9). Previous studies have demonstrated that copper $(\mathrm{Cu})$ is a strong inducer of reactive oxygen species (ROS) and high ROS activity can damage DNA, protein and lipids, leading to apoptosis $(10,11)$. In addition, breast cancer tumors have been reported to have high tissue levels of copper (12-15). Thus, copper and the AKT and JNK signaling pathways are suggested as potential therapeutic targets in breast cancer chemoprevention and chemotherapy. Disulfiram (DS) has been used as the first-line anti-alcoholism drug for over 70 years with no clear toxicity (16). Previous studies indicated that DS can penetrate and intracellularly chelate $\mathrm{Cu}$ forming a new complex, which in turn inhibits cell proliferation and induces apoptosis via AKT, JNK and ROS regulation (15,17-20). However, whether the $\mathrm{DS} / \mathrm{Cu}$ complex exerts chemopreventive effects on breast cancer remains elusive. Thus, the present study aimed to investigate the potential chemopreventive effects of $\mathrm{DS} / \mathrm{Cu}$ on breast cancer.

The MMTV-erbB2 transgenic mouse model, which overexpresses the wild-type erbB2/neu proto-oncogene, is able to spontaneously produce erbB2-positive mammary cancer tumors due to the MMTV promoter-induced overexpressed erbB2 gene in their mammary glands (21). Thus far, this mouse model has been widely used to evaluate the efficacy of potential chemopreventive drugs and investigate relative underlying mechanisms $(22,23)$. In a previous study, it was observed that high doses of dietary soy isoflavones delay tumor development in MMTV-erbB2 transgenic mice (24). In the present study, in order to investigate the potential of using DS/Cu in 
erbB2-positive breast cancer chemoprevention, the effect of $\mathrm{DS} / \mathrm{Cu}$ treatment on the development of mammary tumors was examined in MMTV-erbB2 transgenic mice. In the present study, DS/Cu was used at a low dose $(50 \mathrm{mg} / \mathrm{kg}$ body weight for eight weeks) with minimum toxicity risk, good medication adherence and thereby acceptable risk-benefit ratio, which are all factors critical to the success of a cancer risk reduction intervention in clinical practice. The use of $\mathrm{DS} / \mathrm{Cu}$ was hypothesized to delay the development of mammary tumors in MMTV-erbB2 transgenic mice.

\section{Materials and methods}

Reagents and antibodies. DS, copper (II) chloride $\left(\mathrm{CuCl}_{2}\right)$ and dimethyl sulfoxide were obtained from Sigma-Aldrich (St. Louis, MO, USA). The following antibodies were purchased from Cell Signaling Technology (Danvers, MA, USA): Rabbit monoclonal Akt (cat. no. 4685; 11E7), p-Akt (Ser 473; cat. no. 4058; 193H12), JNK (cat. no. 9258; 56G8) and p-JNK (Thr183/Tyr185; cat. no. 4668; 81E11). The following antibodies were purchased from Santa Cruz Biotechnology, Inc. (Dallas, TX, USA): Rabbit polyclonal immunoglobulin (Ig)G cyclin D1 (sc-718; M-20), pP38 (Tyr182; sc-101759), nuclear factor $\kappa \mathrm{B}(\mathrm{NF}-\kappa \mathrm{B}$ p65; sc-7151; H-286) and mouse monoclonal IgG1 $\beta$-actin (sc-8432; C-2). Horseradish peroxidase (HRP)-labeled goat anti-rabbit (cat. no. 31466) and goat anti-mouse (\#31431) secondary antibodies were obtained from Thermo Fisher Scientific (Waltham, MA, USA). erbB2 was obtained from Neomarkers, Inc. (Fremont, CA, USA). The following reagents were obtained from Maixin Biotech Co., (Fuzhou, China): 10\% neutral formalin, ethanol, citrate buffer, xylene, $\mathrm{H}_{2} \mathrm{O}_{2}$, paraffin, methanol, normal serum, eosin, hematoxylin, chloroform, glacial acetic acid and carmine alum. Tris-buffered saline/Tween 20 (TBST) was purchased from BD Chemical (Greenwood Village, CO, USA) and DMEM/ F12, fetal bovine serum, penicillin and streptomycin were ordered from Gibco-BRL (Carlsbad, CA, USA).

Animals. The present study was approved by the ethics committee of The First Affiliated Hospital of Henan University of Science and Technology (Luoyang, China). All animal experiments were conducted in accordance with National Institutes of Health guidelines. A total of 50 six-week-old female FVB/N-Tg (MMTV-erbB2) 202Mul/J mice were purchased from The Jackson Laboratory (Stock no. 002376; Bar Harbor, ME, USA). Average weight at 20 weeks was $20 \pm 2 \mathrm{~g}$. Mice were kept under a 12-h reversed light/dark cycle and the temperature was maintained at $22^{\circ} \mathrm{C}$ in the animal house facility, which was located in the Molecular Biology Core Laboratory (The First Affiliated Hospital of Henan University of Science and Technology, Luoyang, China). The mice were fed an AIN-93G pellet diet (D10012G; Research Diets, New Brunswick, NJ, USA) with free access to water. Based on previous studies and human therapeutic doses $(16,18)$, mice were treated with DS $(50 \mathrm{mg} / \mathrm{kg} /$ day $) / \mathrm{Cu}(0.1 \mathrm{mg} / \mathrm{kg} / \mathrm{day})$ or vehicle (100 $\mu 1$ normal saline) for 6 days/week from the age of 20-28 weeks via subcutaneous injection ( $n=25 /$ group). Subsequent to eight weeks of treatment (28 weeks of age), five mice from each group were sacrificed through cervical vertebra dislocation following intraperitoneal anaesthesia with propofol (100 mg/kg; GuoRui Pharmaceutical Co., Ltd, Chengdu, China), the right abdominal mammary gland was whole mounted and the right thoracic mammary gland was fixed in $10 \%$ neutral formalin for immunohistochemistry, whereas the rest of the tissue was immediately frozen in liquid nitrogen for protein analyses. The remaining mice in each group were monitored twice a week to the end of the experiment. Tumor development and tumor volume were recorded. The first sign of tumor development was a palpable solid tumor with a volume of $100 \mathrm{~mm}^{3}$. The tumor-free interval was defined as the time from birth until the first tumor occurred. In order to alleviate suffering, the mice were sacrificed by cervical dislocation under intraperitoneal anaesthesia with propofol $(100 \mathrm{mg} / \mathrm{kg}$ ) prior to the tumor diameter reaching $1.5 \mathrm{~cm}$, which occurred $\sim 6$ weeks following the development of palpable tumors. Following 6 weeks the mice were sacrificed and the tumors were harvested and weighed.

Cell culture. The human breast cancer cells BT474 (erbB2 $\left.2^{\text {high }}\right)$, human microvascular endothelial cells (HMECs) and normal breast epithelial cells (MCF10A) were purchased from the China Center for Type Cell Culture Collection (Wuhan University; Wuhan, China), while the EM01 cell line derived from MMTV-erbB2 mammary tumors was established in The Molecular Biology Core Laboratory of the First Affiliated Hospital of Henan University of Science and Technology. All cell lines were maintained in DMEM/F12 culture medium supplemented with $10 \%$ fetal bovine serum, penicillin (100 U/ml) and streptomycin $(100 \mu \mathrm{g} / \mathrm{ml})$ in a humidified Thermo Forma Series II Water Jacket incubator $\left(37^{\circ} \mathrm{C}, 5 \%\right.$ carbon dioxide; Thermo Fisher Scientific).

MTS assay. In vitro cell proliferation was determined by the MTS assay using the Cell Titer 96 AQueous One Solution Cell Proliferation Assay System (Promega Corporation, Madison, WI, USA). Briefly, cells were seeded into 96-well plates (500 cells/well). After $24 \mathrm{~h}$, cells were treated with DS $(0-10 \mu \mathrm{mol} / \mathrm{l}) / \mathrm{Cu}(0.2 \mu \mathrm{mol} / \mathrm{l})$ for $24 \mathrm{~h}$. Control cells were treated with $0.1 \%$ dimethyl sulfoxide in culture medium. Subsequently, the MTS assay was conducted in order to examine the growth of different cell groups and absorbance was read at $540 \mathrm{~nm}$ using a 96-well Thermo Scientific Multiskan Ascent Microplate reader (Thermo Fisher Scientific) according to the manufacturer's instructions.

Histology and immunohistochemistry. Mammary glands were fixed in $10 \%$ neutral formalin, dehydrated with a graded ethanol series and embedded in paraffin. Sections $(5 \mu \mathrm{m})$ were stained with hematoxylin and eosin for histological analysis or processed for immunohistochemistry. Immunohistochemistry was performed using the Vectastain Elite avidin-biotin complex (ABC) kit (Vector Laboratories, Inc., Burlingame, CA, USA) in accordance with the manufacturer's instructions. Mammary gland sections were deparaffinized and rehydrated by successive washes with xylene and a graded ethanol series. Antigen retrieval was conducted in citrate buffer ( $\mathrm{pH}$ 6.0) at $100^{\circ} \mathrm{C}$ for $30 \mathrm{~min}$ in a steamer, endogenous peroxidase activity was quenched with $3 \% \mathrm{H}_{2} \mathrm{O}_{2}$ in methanol for $10 \mathrm{~min}$ at room temperature and nonspecific binding was blocked with $10 \%$ normal serum. The sections were incubated at $4^{\circ} \mathrm{C}$ overnight 
A

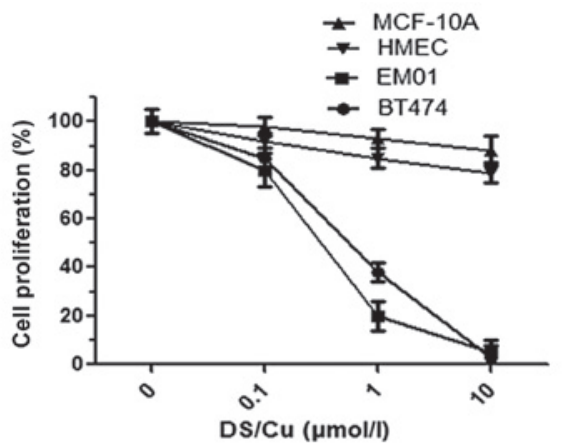

B

BT474

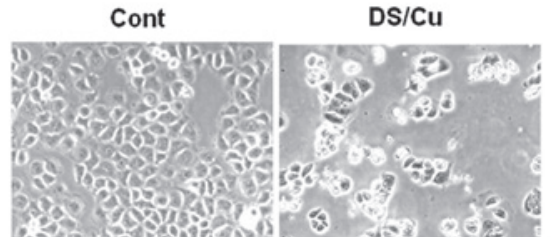

EM01

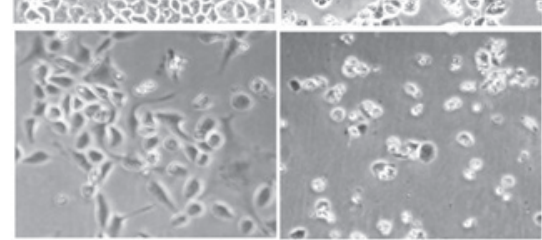

MCF-10A

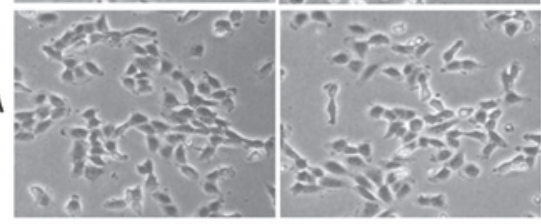

HMECS

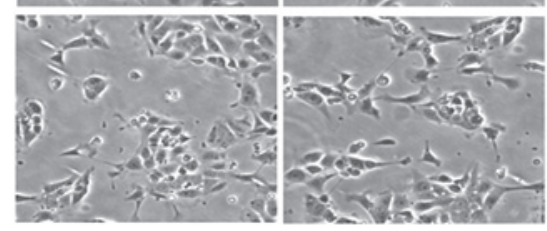

Figure 1. (A) MTS assay. The normal HMECs, the immortalized MCF10A cells, the human breast cancer cell line BT474 (erbB2 ${ }^{\text {high }}$ ) and EM01 breast cancer primary culture cells were treated with DS $(0-10 \mu \mathrm{mol} / 1) / \mathrm{Cu}$ $(0.2 \mu \mathrm{mol} / \mathrm{l})$ for $24 \mathrm{~h}$, followed by the MTS assay. (B) The morphology of BC cell lines following $24 \mathrm{~h}$ drug exposure (magnification, $\mathrm{x} 100$ ). HMEC, human microvascular endothelial cells; $\mathrm{DS} / \mathrm{Cu}$, disulfiram/copper; $\mathrm{BC}$, breast cancer.

with the primary antibodies, then subsequently with the biotinylated secondary antibody for $1 \mathrm{~h}$, followed by ABC reagent (Vector Laboratories, Inc.) and diaminobenzidine. Slides were counterstained with hematoxylin.

Bromodeoxyuridine (BrdU) and terminal deoxynucleotidyl transferase-mediated dUTP nick end labeling (TUNEL) assay. The BrdU assay was conducted using the BrdU Cell Proliferation Assay kit (BD Biosciences, San Jose, CA, USA). Mice were injected intraperitoneally with $200 \mu 1(3 \mathrm{mg} / \mathrm{ml}) \mathrm{BrdU}$ solution $2 \mathrm{~h}$ prior to scarification. Subsequently, cellular incorporation of BrdU was detected by immunohistochemistry using anti-BrdU-specific antibodies. The TUNEL assay was performed using the ApopTag Peroxidase In situ Apoptosis Detection kit (Merck Millipore, Darmstadt, Germany). Briefly, following deparaffinization and hydration, the tissue was incubated with Working Strength TdT enzyme, Working Strength Stop/Wash buffer, conjugated with antidigoxigenenin, and then stained with peroxidase substrate. The tissue was then

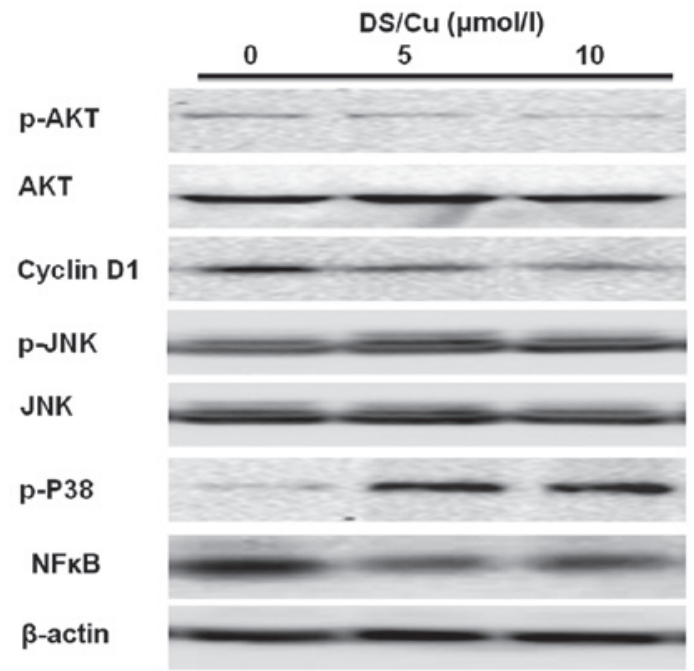

Figure 2. The effect of DS/Cu on AKT, JNK, cyclin D1 and NF- $\mathrm{KB}$ pathways in vitro. The BC cells were exposed to DS $(0,5$ and $10 \mu \mathrm{mol} / 1) / \mathrm{Cu}(0.2 \mu \mathrm{mol} / 1)$ for $24 \mathrm{~h}$. The expression levels and phosphorylation status of proteins AKT, JNK, cyclin D1 and NF- $\mathrm{kB}$ pathways were detected by western blot. $\beta$-actin was used as loading control. DS/Cu, disulfiram/copper; AKT, protein kinase B; JNK, c-Jun N-terminal kinase; $\mathrm{NF \kappa B}$; nuclear factor $\kappa \mathrm{B}$; $\mathrm{BC}$, breast cancer.

mounted under a glass coverslip in Permount and viewed under a Nikon 80i microscope (Nikon Corp. Tokyo, Japan).

Mammary whole-mount preparation. Mammary tissue was mounted onto a glass slide and fixed in Carnoy's fix solution (100\% ethanol/chloroform/glacial acetic acid 6:3:1) overnight. The sample was then rehydrated in 70, 50,30 and 10\% ethanol for 30 min each, stained overnight in carmine alum stain, then dehydrated with 70, 95 and 100\% ethanol and cleared in xylene overnight. Following this, the glass slide was analyzed under a DTM 1200 digital camera (Nikon Corp.) mounted on a Nikon C-LEDS microscope (Nikon Corp.).

Western blot analysis. Cells or tissues were homogenized at $4^{\circ} \mathrm{C}$ in radioimmunoprecipitation assay lysis buffer (Thermo Fisher Scientific) for extracting total protein. The protein was quantitated using a bicinchoninic acid protein assay kit (Pierce Biotechnology, Inc., Rockford, IL, USA). Equal samples (50 $\mu \mathrm{g}$ protein) were electrophoresed through 10-12\% SDS-PAGE gels and transferred to nitrocellulose membranes (Millipore, Boston, MA, USA). The membranes were then blocked in 5\% non-fat powdered milk/TBST for $1 \mathrm{~h}$ and then incubated overnight with the relevant primary antibodies at $4^{\circ} \mathrm{C}$ overnight (Akt, 1:1,000; p-Akt, 1:1,000; JNK, 1:1,000; p-JNK, 1:1,000; Cyclin D1, 1:2,000; pP38, 1:500; NF-кB p65, 1:500; p65, 1:500; and $\beta$-actin, 1:3,000). The membranes were then washed with TBST and incubated with goat anti-mouse/rabbit HRP-labeled secondary antibodies $(1: 5,000)$ for $1.5 \mathrm{~h}$ at room temperature. The membranes were then washed again with TBST and visualized by using electrochemiluminescence (Thermo Fisher Scientific).

Statistical analysis. Statistical analyses were performed using GraphPad Prism 5.0 software (GraphPad, Inc., La Jolla, CA, USA). Tumor-free intervals for survival curves were calculated using the Kaplan-Meier method. The significance of 
A

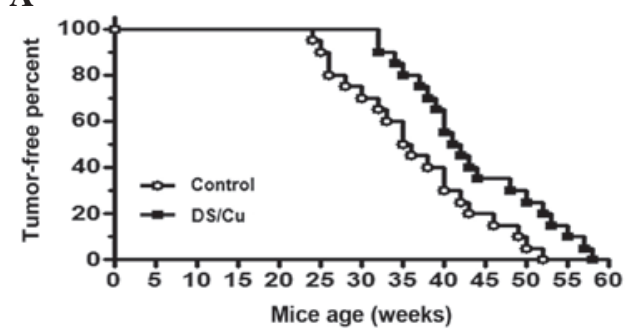

B

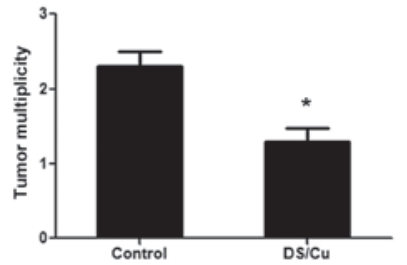

C

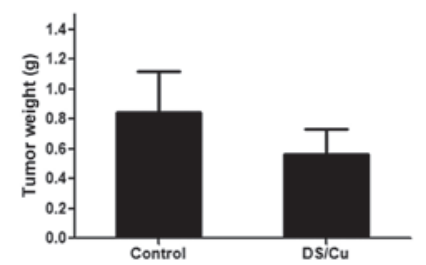

Figure 3. Effects of short-term treatment with DS/Cu on mammary tumors of MMTV-erbB2 mice. MMTV-erbB2 transgenic mice were treated with vehicle (control) or DS (50 mg/kg/day)/Cu (0.1 mg/kg/day) for 6 days $/$ week from age 20-28 weeks by subcutaneous injection ( $\mathrm{n}=25 /$ group). Tumors were measured twice a week to determine growth. (A) Tumor-free distribution, (B) average tumor multiplicity, (C) average tumor weight. ${ }^{~} \mathrm{P}<0.05 . \mathrm{DS} / \mathrm{Cu}$, disulfiram/copper.

A

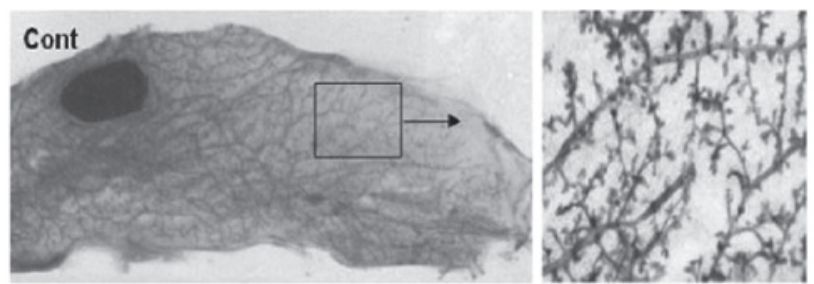

B

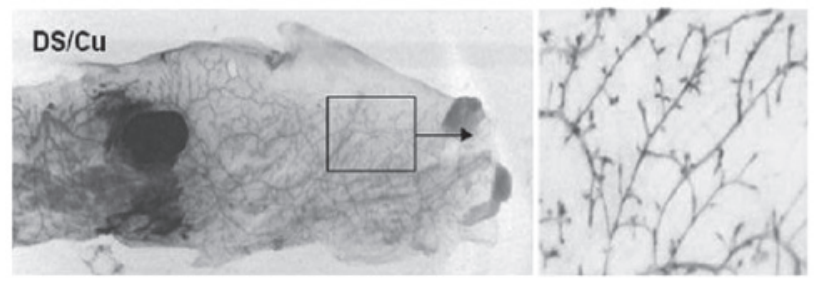

Figure 4. Representative mammary whole mounts of (A) control and (B) DS/Cu-treated mice. MMTV-erbB2 mice were treated with saline (control) or DS $(50 \mathrm{mg} / \mathrm{kg} / \mathrm{day}) / \mathrm{Cu}(0.1 \mathrm{mg} / \mathrm{kg} / \mathrm{day}$ via subcutaneous injection) starting from age 20-28 weeks. Mammary glands were harvested and processed at 28 weeks of age. Whole mounts from five mice from each group were examined. $\mathrm{DS} / \mathrm{Cu}$, disulfiram/copper.

the differences between the groups was determined using a two-sided Student's t-test. $\mathrm{P} \leq 0.05$ was considered to indicate a statistically significant difference.

\section{Results}

DS/Cu inhibits growth of BC cells but not of normal cells. In cancer chemoprevention, the ability to exert cytotoxicity in tumor cells but not in normal cells is an important criterion for novel chemopreventative drugs $(25,26)$. As breast cancer cells and tissues accumulate high levels of copper (12), this can be utilized for the enhancement of copper in breast cancer cells as a novel chemopreventive strategy. DS is known to be able to bind copper, and the DS/Cu complex has been reported to be toxic to various cancer cells and xenografts $(11,18)$. However, whether the DS/Cu complex selectively targets breast cancer cells while sparing normal mammary cells remains to be investigated.

In the present study, normal cells (HMECs), immortalized normal cells [normal breast epithelial cells (MCF10A)] (27), malignant cells [human breast cancer cells BT474 (erbB2 $\left.{ }^{\text {high }}\right)$ ] and EM01 (erbB2 ${ }^{\text {high }}$ ) breast cancer primary culture cells from MMTV-erbB2 transgenic mice were used to determine this issue. These cell lines were incubated with the DS $(0$, $0.1,1$ or $10 \mu \mathrm{mol} / \mathrm{l}) / \mathrm{Cu}(0.2 \mu \mathrm{mol} / 1)$ complex for $24 \mathrm{~h}$ and were then examined using the MTS assay. As demonstrated in Fig. 1, the effects of DS-Cu treatment on the proliferation of the BT474 cells and EM01 cells were observed to be dose-dependent. Compared with these two cell lines, the normal HMECs and MCF10A cells are significantly more resistant to the DS/Cu complex. These results suggested that the DS/Cu complex has anti-cancer activity selectively in breast cancer cells over normal cells.

The DS/Cu complex inhibits cell growth and induces apoptosis via activating the JNK pathway and inhibiting AKT, cyclin D1 and $N F-\kappa B$ signaling. Tumor inhibition is known to commonly occur via two mechanisms: i) Proliferation inhibition and ii) apoptosis promotion (28). Whether these two mechanisms serve a role in $\mathrm{DS} / \mathrm{Cu}$ complex-induced tumor inhibition remains elusive. Regulation of AKT, cyclin D1, NF- $\kappa \mathrm{B}$ and JNK signaling has been reported to be the predominant mechanism underlying DS/Cu complex activity $(15,17,19,20,29)$. Thus, in the present study, BT474 cells were incubated with 0,5 or $10 \mu \mathrm{mol} / 1 \mathrm{DS} / \mathrm{Cu}(0.2 \mu \mathrm{mol} / 1)$ complex for $24 \mathrm{~h}$, and the treated cells were then analyzed using western blot analysis and TUNEL staining. Consistent with previous studies $(10,11,18)$, TUNEL staining identified a significantly greater number of apoptotic cells in DS (5 and $10 \mu \mathrm{mol} / \mathrm{l}) / \mathrm{Cu}$ $(0.2 \mu \mathrm{mol} / \mathrm{l})$ complex-treated cells. DS/Cu complex treatment resulted in a significant upregulation of pJNK and pP38 expression and a downregulation of $\mathrm{p}-\mathrm{AKT}$, cell proliferation marker cyclin D1 and NF- $\kappa$ B expression (Fig. 2). Furthermore, the effect of the DS/Cu complex on these protein expression levels in the normal HMECs and MCF10A cells was also measured, and no significant results were observed (data not shown). These observations suggested that the DS/Cu complex may upregulate JNK and inhibit AKT, cyclin D1 and NF- $\kappa \mathrm{B}$ signaling, which in turn activate apoptosis and suppress proliferation in breast cancer cells.

$D S / C u$ delays the development of mammary tumors in $M M T V$-erbB2 mice. To determine the cancer-preventive effect of the DS/Cu complex, $50 \mathrm{MMTV}$-erbB2 mice were equally randomized into two groups. One group of mice were treated with the vehicle, while the other one was treated with DS (50 mg/ $\mathrm{kg} /$ day $) / \mathrm{Cu}(0.1 \mathrm{mg} / \mathrm{kg} /$ day $)$ for 6 days/week from age 20 weeks to 28 weeks by subcutaneous injection ( $n=25 /$ group). Data for the development of mammary tumors was collected, and it was observed that the DS/Cu-treated mice took 32-58 weeks to begin to develop palpable tumors, with a 


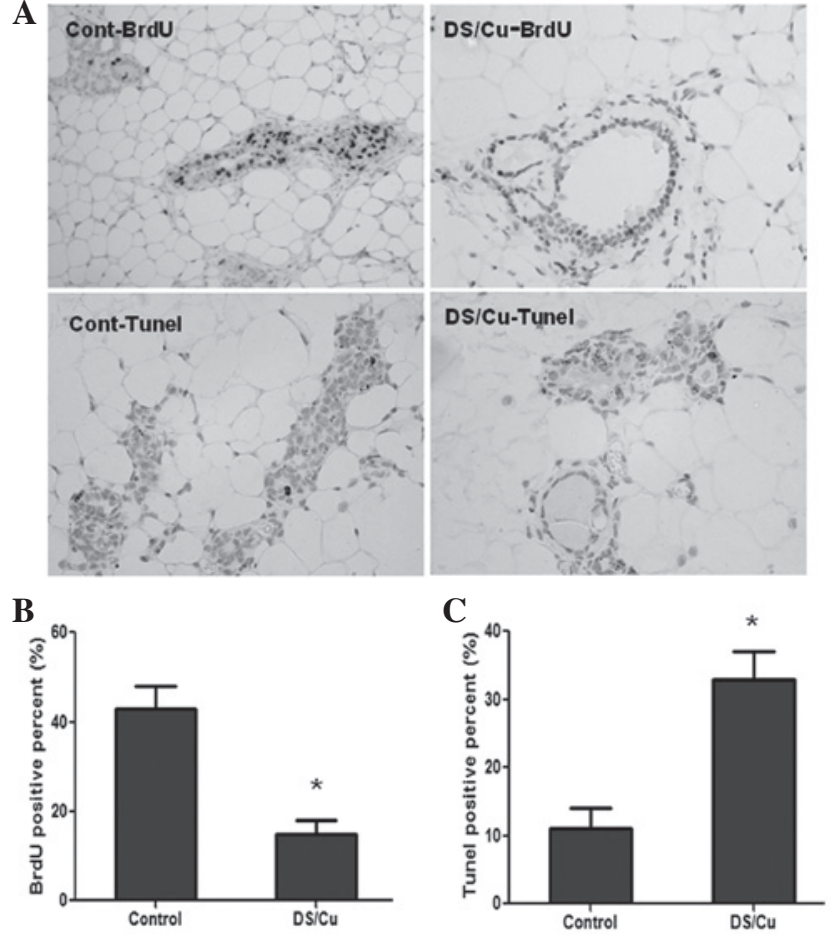

Figure 5. DS/Cu treatment increases BrdU staining and reduces TUNEL staining. (A) Representative image of BrdU and TUNEL staining in mammary glands treated with DS/Cu or saline (control). (B) The BrdU staining percentage. (C) Percentage of positive TUNEL staining. ${ }^{*} \mathrm{P}<0.05$. DS/Cu, disulfiram/copper; TUNEL, terminal deoxynucleotidyl transferase dUTP nick end labeling; BrdU, bromodeoxyuridine.

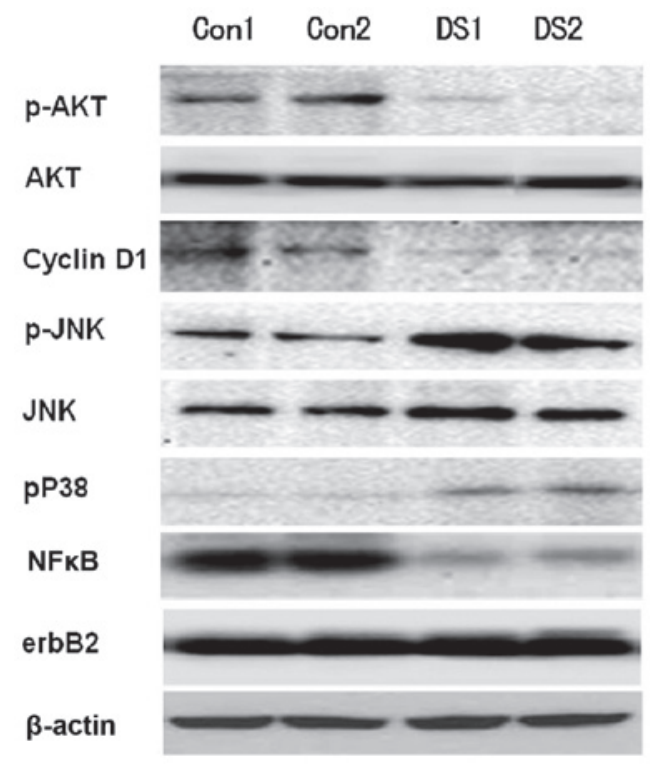

Figure 6. Effect of DS/Cu on AKT, JNK, cyclin D1, erbB2 and NFKB pathways in mammary tissues of MMTV-erbB2 transgenic mice. Protein lysates were prepared from mammary tissues of 28-week-old MMTV-erbB2 mice treated with saline or DS/Cu. Protein levels of indicated markers were detected by western blot analysis. $\beta$-actin was used as loading control $\mathrm{DS} / \mathrm{Cu}$, disulfiram/copper; p-JNK, phosphorylated c-Jun N-terminal kinase; $\mathrm{NF} \kappa \mathrm{B}$; nuclear factor $\kappa \mathrm{B}$; Con, control.

median time of 292 days, while the mice in the vehicle group began to develop tumors after 24-52 weeks, with a median time of 265 days. There was a significant delay in tumor development between the two groups $(\mathrm{P}=0.0191)$ (Fig. 3A). The tumor multiplicity and tumor weight of the mice between the two groups was also measured, and it was identified that $\mathrm{DS} / \mathrm{Cu}$ treatment significantly reduced the average tumor multiplicity and nonsignificantly reduced tumor weight. As presented in Fig. 3B, the tumor multiplicity (number of tumors in each mouse) in the $\mathrm{DS} / \mathrm{Cu}$ treatment group $(1.5 \pm 0.19)$ was significantly lower than that in control group (2.3 \pm 0.18$)$ $(\mathrm{P}<0.05)$. The tumor weight in the $\mathrm{DS} / \mathrm{Cu}$ treatment group $(0.51 \pm 0.19 \mathrm{~g})$ was nonsignificantly lower than that of the control group $(0.84 \pm 0.28 \mathrm{~g})$ (Fig. 3C). Compared with the untreated MMTV-erbB2 mice, common toxicities (rash, dry skin or diarrhea) nor weight loss were observed in mice treated with either $\mathrm{DS} / \mathrm{Cu}$ or vehicle. These results suggested that short term exposure of $\mathrm{DS} / \mathrm{Cu}$ at low doses may delay the development of mammary tumors in MMTV-erbB2 mice.

DS/Cu delays mammary gland development, inhibits proliferation and induces apoptosis of mammary tumors in $M M T V$-erbB 2 mice. DS/Cu has been previously demonstrated to exert its biological activity primarily through proliferation inhibition and apoptosis promotion $(18,30)$; thus, the present study aimed to further verify this in vivo. To investigate this, following 8 weeks of treatment, the mammary glands at age 28 weeks were examined for the ductal architecture, proliferation and apoptosis using whole mount analysis, BrdU assay and TUNEL staining, respectively. As presented in Fig. 4, compared with the vehicle-treated mammary glands, those treated with $\mathrm{DS} / \mathrm{Cu}$ displayed significantly reduced lateral branching and alveolar structures. As expected, the mammary glands and tumors from the DS/Cu-treated group demonstrated significantly lower proliferation and higher apoptotic rates than those of vehicle-treated group (Fig. 5). These data indicated that $\mathrm{DS} / \mathrm{Cu}$ suppresses mammary tumorigenesis and mammary tumor growth in MMTV-erbB2 mice through proliferation inhibition and apoptosis promotion.

$D S / C u$ activates JNK signaling while suppressing AKT, cyclin D1 and $N F-\kappa B$ signaling in the mammary glands of $M M T V$-erbB2 mice. Having verified the inhibitory effect and underlying mechanism of DS/Cu on breast cancer cells in vitro, it was hypothesized that $\mathrm{DS} / \mathrm{Cu}$ may exert similar effects on the mammary glands in MMTV-erbB2 mice. To clarify this, the mammary glands obtained from the mice receiving 8 weeks of $\mathrm{DS} / \mathrm{Cu}$ treatment were analyzed for the expression of JNK, AKT and NF- $\mathrm{NB}$ signaling pathways using western blot analysis. The expression levels of the cell proliferation marker cyclin D1 in mammary glands were also measured. Compared with the control group, increased pJNK and pP38 expression levels, and reduced p-AKT, cyclin D1 and NF- $\kappa \mathrm{B}$ protein expression levels were observed in the mammary glands of mice treated with $\mathrm{DS} / \mathrm{Cu}$ (Fig. 6). These data are consistent with the in vitro results. These observations are also in support of the hypothesis that DS/Cu may exert chemopreventive effects through two ways: Proliferation inhibition via regulating AKT and cell cycle signaling, and apoptosis promotion via activating $\mathrm{JNK}$ while inhibiting $\mathrm{NF}-\kappa \mathrm{B}$ signaling.

DS/Cu does not interfere with MMTV promoter-driven erbB2 expression. To exclude the possibility that the suppressing 
effect of $\mathrm{DS} / \mathrm{Cu}$ was facilitated by the reduced expression of the erbB2 transgene, the erbB2 protein expression levels were further investigated in mammary glands treated with $\mathrm{DS} / \mathrm{Cu}$ or the vehicle using western blot analysis. It was observed that erbB2 protein expression remained unaltered in the presence of $\mathrm{DS} / \mathrm{Cu}$ in vivo (Fig. 6), which indicated that the effects of $\mathrm{DS} / \mathrm{Cu}$ are not due to a reduction in erbB2 transgene expression.

\section{Discussion}

In the present study, the potential chemopreventive effects of $\mathrm{DS} / \mathrm{Cu}$ exposure on the development of erbB2 positive tumors were investigated in MMTV-erbB2 transgenic mice. An age of 20 weeks is considered as the premalignant phase in mice (21), and the results of the present study demonstrated that short term $\mathrm{DS} / \mathrm{Cu}$ exposure at the premalignant phase delayed the mammary tumor development in MMTV-erbB2 transgenic mice. This is suggested to be based on growth inhibition and apoptosis activation in mammary glands. The results indicated that DS may suppress erbB2-positive mammary tumorigenesis in MMTV-erbB2 mice by preventing premalignant lesions, via proliferation inhibition and apoptosis promotion. The underlying mechanisms of this may include suppression of $\mathrm{AKT}$, cyclin D1 and NF- $\mathrm{BB}$ signaling and activation of the JNK pathway.

Short-term, low-dose chemoprevention can improve patient compliance, in addition to minimizing chronic side effects, making it a suitable chemopreventive strategy (26). It was hypothesized that short-term, low-dose $\mathrm{DS} / \mathrm{Cu}$ intervention in the premalignant phase may delay the onset of mammary tumor development. To verify this hypothesis, the MMTV-erbB2 transgenic mouse model was used, which mimicked carcinogenesis of human erbB2-positive breast cancer. The mice were treated with $\mathrm{DS} / \mathrm{Cu}$ or vehicle for 2 months from the age of 20-28 weeks. As the mice usually develop tumors from 6 months of age, the treatment phase was considered to be in the premalignant phase in the mice. It was observed that 8 weeks of DS treatment delayed the development of mammary tumors by 4 weeks (mean age of tumor onset, 38 and 42 weeks in DS-treated and vehicle-treated mice, respectively), and all vehicle-treated and DS-treated mice had developed tumors at the conclusion of the experiment (58 weeks).

It is of note that the delay time (4 weeks) in tumor onset is shorter than the treatment time ( 8 weeks). The following reasons are suggested to explain this disparity. Firstly, the dose of $\mathrm{DS} / \mathrm{Cu}$ used was relatively low, which may not completely prevent premalignant lesions. Secondly, DS/Cu itself may not have the capacity to completely suppress mammary tumorigenesis, which is supported by the observation that MMTV-erbB2 mice treated with $\mathrm{DS} / \mathrm{Cu}$ did develop tumors. Additionally, these mice may have developed resistance following constant exposure to low doses of $\mathrm{DS} / \mathrm{Cu}$. Carrying the inactivated neu/c-erbB2 proto-oncogene under the transcriptional control of the MMTV, the MMTV-erbB2 mice have a constant tendency to develop tumors following puberty (21). For these reasons, although all vehicle- and DS/Cu-treated mice had developed tumors by the conclusion of the experiment (58 weeks), the median 4-week delay following the 8-week DS treatment indicates that DS exposure may in part be chemopreventive via the suppression of premalignant lesions.

To verify this, the effect of $\mathrm{DS} / \mathrm{Cu}$ was investigated in normal or malignant mammary cells in vitro and by measuring mammary gland development in vivo. Since proliferative and apoptotic promotion are the two mechanisms involved in tumor delay (28), alterations in cell proliferation and apoptosis were examined in the present study. As expected, significant growth inhibition and elevated apoptosis were observed in mammary gland tissue and breast cancer cells. Due to the fact that DS/Cu has no apparent effect on normal human mammary epithelial cells, the results suggested that DS/Cu may suppress mammary tumor development by the inhibition of cell proliferation and apoptotic activation of premalignant cells in the mammary gland. In agreement with this hypothesis, further experiments identified that mammary glands treated with $\mathrm{DS} / \mathrm{Cu}$ displayed fewer premalignant lesions than those treated with the vehicle.

The NF- $\mathrm{BB}$ - and AKT-mediated promotion of apoptosis and the activation of JNK-mediated inhibition of proliferation have been previously reported in various studies to be involved in the biological activity of $\mathrm{DS} / \mathrm{Cu}(11,15,17,18,20,30,31)$. Since these signaling pathways have been reported to be regulated at the level of protein-protein interaction $(11,17,18)$, the relative protein expression levels but not mRNA levels were measured in mammary gland tissues in vivo and in normal or malignant mammary cells in vitro. In agreement with previous studies, the present study observed that DS/Cu suppressed proliferation and promoted apoptosis in the breast cancer cells, which was associated with the reduction of the AKT, cyclin D1 and NF- $\kappa$ B signaling pathways and the activation of the JNK pathway. This suggested that DS/Cu may inhibit proliferation via inhibition of AKT and cyclin D1 signaling and promote apoptosis via JNK activation and NF- $\kappa \mathrm{B}$ signaling suppression.

There are several limitations in the present study: The dose of DS/Cu administrated was not high enough to exhibit significant chemopreventive effects. However, since good patient compliance and minimal side effects are two basic requirements for cancer chemoprevention strategy $(25,26,32,33)$, high dose level intervention will likely limit its clinical applicability. Additional protocols in which $\mathrm{DS} / \mathrm{Cu}$ is administered at a variety of dose levels and for various phases are required in order to achieve an ideal benefit risk ratio in future studies. However, the present study does suggest that short-term, low-dose $\mathrm{DS} / \mathrm{Cu}$ exposure at the premalignant phase may be a novel strategy to prevent the development of erbB2-positive breast cancer, which warrants further investigation.

\section{References}

1. DeSantis C, Ma J, Bryan L and Jemal A: Breast cancer statistics, 2013. CA Cancer J Clin 64: 52-62, 2014.

2. Green VL: Breast cancer risk assessment, prevention and the future. Obstet Gynecol Clin North Am 40: 525-549, 2013.

3. Allen-Petersen BL, Carter CJ, Ohm AM and Reyland ME: Protein kinase Cdelta is required for ErbB2-driven mammary gland tumorigenesis and negatively correlates with prognosis in human breast cancer. Oncogene 33: 1306-1315, 2014.

4. Chlebowski RT, Col N, Winer EP, Collyar DE, Cummings SR, Vogel VG III, Burstein HJ, Eisen A, Lipkus I and Pfister DG: American Society of clinical oncology technology assessment of pharmacologic interventions for breast cancer risk reduction including tamoxifen, raloxifene and aromatase inhibition. J Clin Oncol 20: 3328-3343, 2002. 
5. Visvanathan K, Hurley P and Bantug E: Use of pharmacologic interventions for breast cancer risk reduction: american society of clinical oncology clinical practice guideline. J Clin Oncol 31: 2942-2962, 2013

6. Jordan VC: Tamoxifen as the first targeted long-term adjuvant therapy for breast cancer. Endocr Relat Cancer 21: R235-R246, 2014

7. Sukawa Y, Yamamoto H, Nosho K, et al: HER 2 expression and PI3K-Akt pathway alterations in gastric cancer. Digestion 89: 12-17, 2014.

8. Chiang CT, Way TD, Tsai SJ and Lin JK: Diosgenin, a naturally occurring steroid, suppresses fatty acid synthase expression in HER2-overexpressing breast cancer cells through modulating Akt, mTOR and JNK phosphorylation. FEBS Lett 581: 5735-5742, 2007.

9. Zhang MH, Man HT, Zhao XD, Dong N and Ma SL: Estrogen receptor-positive breast cancer molecular signatures and therapeutic potentials (Review). Biomed Rep 2: 41-52, 2014.

10. Daniel KG, Gupta P, Harbach RH, Guida WC and Dou QP: Organic copper complexes as a new class of proteasome inhibitors and apoptosis inducers in human cancer cells. Biochem Pharmacol 67: 1139-1151, 2004

11. Cen D, Brayton D, Shahandeh B, Meyskens FL Jr and Farmer PJ: Disulfiram facilitates intracellular $\mathrm{Cu}$ uptake and induces apoptosis in human melanoma cells. J Med Chem 47: 6914-6920, 2004.

12. Rizk SL and Sky-Peck HH: Comparison between concentrations of trace elements in normal and neoplastic human breast tissue. Cancer Res 44: 5390-5394, 1984.

13. Daniel KG, Harbach RH, Guida WC and Dou QP: Copper storage diseases: Menkes, Wilsons and cancer. Front Biosci 9: 2652-2662, 2004.

14. Huang YL, Sheu JY and Lin TH: Association between oxidative stress and changes of trace elements in patients with breast cancer. Clin Biochem 32: 131-136, 1999.

15. Zhang H, Chen D, Ringler J, Chen W, Cui QC, Ethier SP, Dou QP and $\mathrm{Wu}$ G: Disulfiram treatment facilitates phosphoinositide 3-kinase inhibition in human breast cancer cells in vitro and in vivo. Cancer Res 70: 3996-4004, 2010.

16. Jørgensen $\mathrm{CH}$, Pedersen B and Tønnesen $\mathrm{H}$ : The efficacy of disulfiram for the treatment of alcohol use disorder. Alcohol Clin Exp Res 35: 1749-1758, 2011

17. Wang W, McLeod HL and Cassidy J: Disulfiram-mediated inhibition of NF-kappaB activity enhances cytotoxicity of 5-fluorouracil in human colorectal cancer cell lines. Int J Cancer 104: 504-511, 2003

18. Chen D, Cui QC, Yang H and Dou QP: Disulfiram, a clinically used anti-alcoholism drug and copper-binding agent, induces apoptotic cell death in breast cancer cultures and xenografts via inhibition of the proteasome activity. Cancer Res 66: 10425-10433, 2006.

19. Doyon G, Zerbato J, Mellors JW and Sluis-Cremer N: Disulfiram reactivates latent HIV-1 expression through depletion of the phosphatase and tensin homolog. AIDS 27: F7-F11, 2013.
20. Conticello C, Martinetti D, Adamo L, et al: Disulfiram, an old drug with new potential therapeutic uses for human hematological malignancies. Int J Cancer 131: 2197-2203, 2012.

21. Ursini-Siegel J, Schade B, Cardiff RD and Muller WJ: Insights from transgenic mouse models of ERBB2-induced breast cancer. Nat Rev Cancer 7: 389-397, 2007.

22. Li Y, Zhang Y, Hill J, Shen Q, Kim HT, Xu X, Hilsenbeck SG, Bissonnette RP, Lamph WW and Brown PH: The Rexinoid LG100268 prevents the development of preinvasive and invasive estrogen receptor negative tumors in MMTV-erbB2 mice. Clin Cancer Res 13: 6224-6231, 2007.

23. Lee HJ, So JY, DeCastro A, Smolarek A, Paul S, Maehr H, Uskokovic M and Suh N: Gemini vitamin D analog suppresses ErbB2-positive mammary tumor growth via inhibition of ErbB2/AKT/ERK signaling. J Steroid Biochem Mol Biol 121: 408-412, 2010

24. Zhang GP, Han D, Liu G, Gao SG, Cai XQ, Duan RH and Feng XS: Effects of soy isoflavone and endogenous oestrogen on breast cancer in MMTV-erbB2 transgenic mice. J Int Med Res 40: 2073-2082, 2012.

25. Wattenberg LW: Chemoprevention of cancer. Cancer Res 45: $1-8,1985$

26. Bertram JS, Kolonel LN and Meyskens FL Jr : Rationale and strategies for chemoprevention of cancer in humans. Cancer Res 47: 3012-3031, 1987.

27. Santner SJ, Dawson PJ, Tait L, Soule HD, Eliason J, Mohamed AN, Wolman SR, Heppner GH and Miller FR: Malignant MCF10CA1 cell lines derived from premalignant human breast epithelial MCF10AT cells. Breast Cancer Res Treat 65: 101-110, 2001

28. Zhu J, Xiong G, Trinkle C and Xu R: Integrated extracellular matrix signaling in mammary gland development and breast cancer progression. Histol Histopathol 2014.

29. Lövborg H, Oberg F, Rickardson L, Gullbo J, Nygren P and Larsson R: Inhibition of proteasome activity, nuclear factor-KappaB translocation and cell survival by the antialcoholism drug disulfiram. Int J Cancer 118: 1577-1580, 2006.

30. Li L, Yang H, Chen D, Cui C and Dou QP: Disulfiram promotes the conversion of carcinogenic cadmium to a proteasome inhibitor with pro-apoptotic activity in human cancer cells. Toxicol Appl Pharmacol 229: 206-214, 2008.

31. Brar SS, Grigg C and Wilson KS: Disulfiram inhibits activating transcription factor/cyclic AMP-responsive element binding protein and human melanoma growth in a metal-dependent manner in vitro, in mice and in a patient with metastatic disease. Mol Cancer Ther 3: 1049-1060, 2004.

32. den Hollander P, Savage MI and Brown PH: Targeted therapy for breast cancer prevention. Front Oncol 3: 250, 2013.

33. Brown P: Prevention: targeted therapy-anastrozole prevents breast cancer. Nat Rev Clin Oncol 11: 127-128, 2014 